\title{
Effect of electrical stimulation on motor nerve regeneration in sciatic nerve ligated-mice
}

\author{
Farzaneh Samiee (1), Mohammad-Reza Zarrindast (2) \\ (1) Biomedical Engineering Faculty, Science and Research Branch, Islamic Azad University, \\ Tehran, Iran; (2) Department of Pharmacology, School of Medicine, Tehran University of \\ Medical sciences, Tehran, Iran \\ This article is distributed under the terms of the Creative Commons Attribution Noncommercial License (CC BY-NC 4.0) which permits \\ any noncommercial use, distribution, and reproduction in any medium, provided the original author(s) and source are credited.
}

\begin{abstract}
The purpose of this study was to investigate the effect of electrical stimulation on sciatic nerve regeneration and functional recovery of target muscles. Mice were randomly divided into 3 groups: ligated without electrical stimulation, ligated with electrical stimulation and control (non-ligated). The unilateral peripheral mononeuropathy was produced on the right hind limb. Sciatic nerve was then electrically stimulated daily for a period of 2 weeks (duration: 0.2 msec, frequency: $100 \mathrm{~Hz}$, amplitude: $15 \mathrm{~mA}$ ). Evoked surface EMG was recorded from biceps femoris (BF) and gluteus maximus (GM) muscles on the 3rd, 7th, 10th and 14th day after sciatic nerve ligation. Muscle force and sensitivity was determined by processing of the recorded EMG signals in time and frequency domains respectively. The results showed electrical stimulation (ES) produced a significant increase in the EMG response of $\mathrm{BF}$, and muscle force significantly increased on the 14 th day $(\mathrm{p}<0.001)$, however no significant difference was found in GM muscle force between experimental groups. This may be due to possible innervation by inferior gluteal nerve. Frequency analysis of BF signals indicates that hyperalgesia remained after 14 days in both ligated groups. On the 14th day no difference in GM muscle sensitivity was found between groups. In conclusion, the results of this study have shown that the electrical stimulation of sciatic nerve accelerates nerve repair and indirectly improves BF muscle force to a comparable level with control without effect on muscle sensitivity. However, ES had no effect on GM muscle force and sensitivity.
\end{abstract}

Key Words: EMG, electrical stimulation, muscle force, muscle sensitivity, ligated mice

Partial or complete loss of sensory and motor function may be induced by injury to peripheral nervous system. Peripheral nerves are able to regenerate following lesion or disease. However, regeneration is not complete and the function rarely returns to pre-injury levels. ${ }^{1,2,3}$ Depending on the age and the severity of the lesion, the nerve repair is limited and different. ${ }^{4,5}$ Electrical stimulation (ES) is a popular treatment, useful to recover from muscle atrophy and also used to evoke functional contractions. Different types of ES such as weak direct current, ${ }^{6}$ high-voltage electrical currents, ${ }^{7}$ alternating currents, ${ }^{8}$ transcutaneous nerve stimulation, ${ }^{9}$ neuromuscular electrical stimulation, ${ }^{10}$ and electromagnetic fields ${ }^{11}$ are also used to promote nerve regeneration and to improve neuromuscular functions, but their precise effects on nerve regrowth are debated. Recent studies in the field of peripheral nerve repair are focused on histological methods. ${ }^{2,7,9}$ Furthermore, a number of investigations regarding neuromuscular recovery following nerve injury, have focused on electrical stimulation of muscles, ${ }^{12,13,29}$ or neuromuscular junction. ${ }^{10}$ Effect of nerve electrical stimulation on related muscle electrophysiology has however received less attention. Surface electromyography (SEMG) is a non-invasive method which is an indirect indicator of the central drive. On the other hand, this method is directly associated with activity of the motor units which are affected by physiological parameters such as motor unit discharge rates, and muscle fiber membrane characteristics. ${ }^{15,16}$ So, the purpose of this study was to investigate the effect of electrical stimulation on sciatic nerve regeneration and functional recovery of target muscles.

\section{Materials and Methods \\ Animals}

Male NMRI mice (20-25g) were housed in groups of 10 in conditions of constant temperature $\left(20 \pm 2^{\circ} \mathrm{C}\right)$ with 


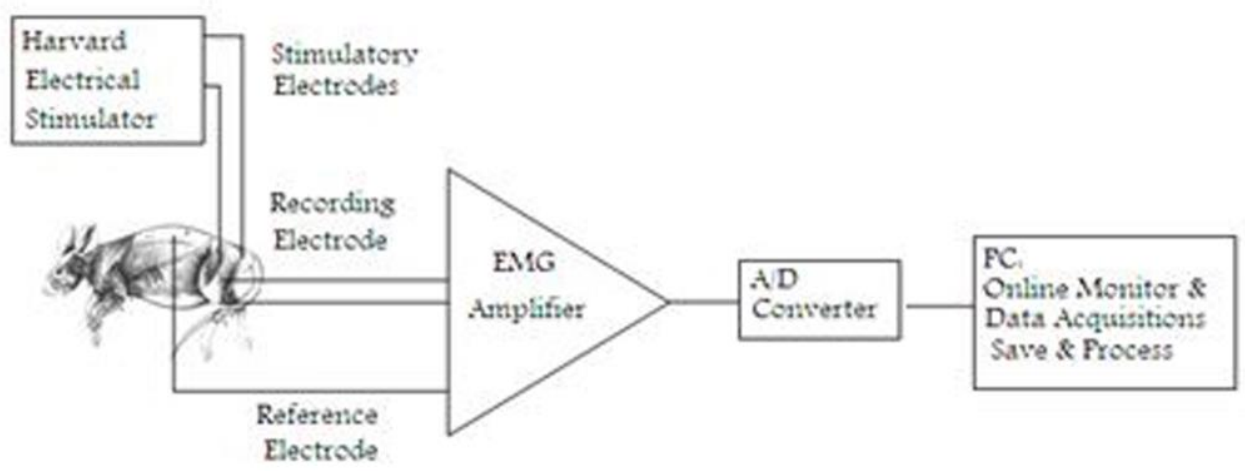

Fig 1. Diagram of the experimental set-up.

12L:12D photoperiod, and were allowed free access to food and water except during the experimental sessions. Each animal was used once only, and was euthanized immediately after the experiments. All experiments were carefully conducted according to the ethical guidelines for the use of experimental pain in conscious animals put forth by the International Association for the Study of Pain.

Surgical procedure for nerve ligation.

The animals were anaesthetized with intraperitoneal injection of sodium thiopental $(40 \mathrm{mg} / \mathrm{kg})$. The unilateral peripheral mononeuropathy to study regeneration of peripheral nerve was produced on the right hind limb, based on the method of Bennet \& Xie (1988) ${ }^{17}$ and Attal et al. (1990). ${ }^{18}$ Then the animal's right sciatic nerve was exposed and freed from the surrounding tissues attachment, and a 2-3 mm long nerve segment was dissected. Only one ligature with fine metal wire was secured around the nerve and the nerve was returned to its bed.

\section{Electrical stimulation of nerve}

This process started from the day of surgery. Under

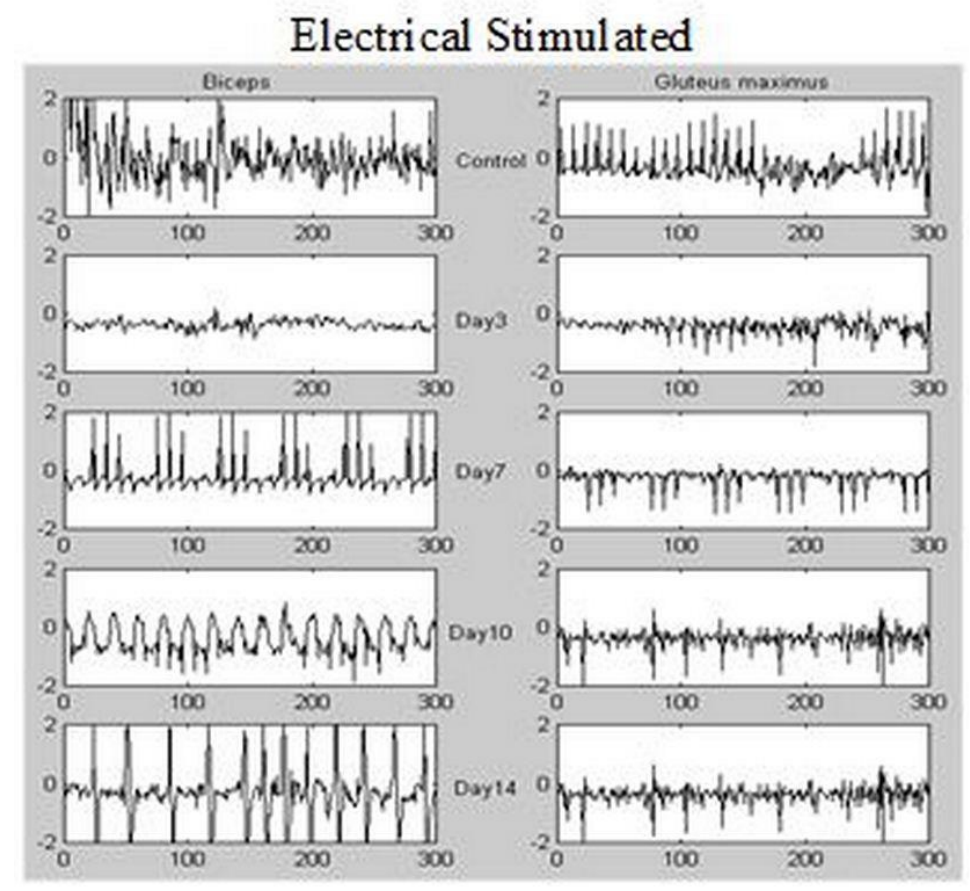

Fig 2. Raw electromyograms (EMGs) of biceps femoris (left side) and gluteus maximus (right side) muscles after electrical stimulation of sciatic nerve on the $3 \mathrm{rd}, 7 \mathrm{th}, 10 \mathrm{th}$ and 14 th day in treated group after nerve ligation in mice. Control EMG signals of biceps femoris and gluteus maximus muscles are shown in upper row. 


\section{Electrical stimulation of ligated sciatic nerve in mice}

Eur J Transl Myol 27 (3): 173-182

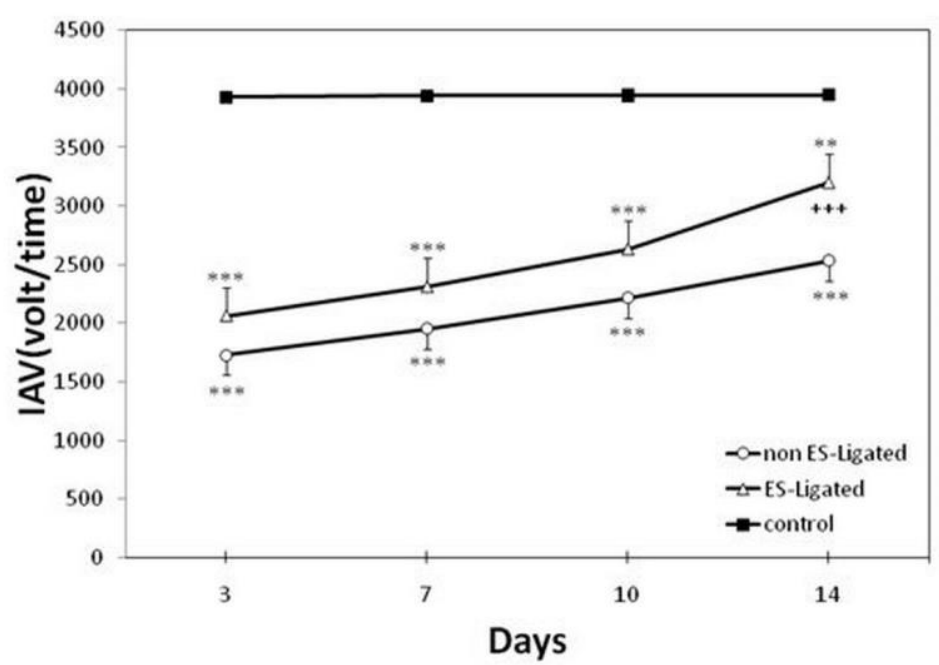

Fig 3. Effect of electrical stimulation on Biceps femoris muscle force. The EMG signal was recorded on the 3rd, 7th, 10th, 14th day after ligation in non ES-Ligated group (o), ES-Ligated group $(\Delta)$ and control group ( - ). Each point is mean \pm SEM of Integral Absolute Value (IAV) for 10 mice. $(* * p<0.01, * * * p<0.001$ different from respective control group, $+++\mathrm{P}<0.001$ different from respective non ES-Ligated group).

light anesthesia with ether, the sciatic nerve was reexposed and gently suspended on a pair of stainlesssteel stimulatory electrodes. The proximal nerve stump was then electrically stimulated for 40 seconds per day (20 pulses/ contraction). The stimulatory pulse (duration: 0.2 millisecon, frequency: $100 \mathrm{~Hz}$, amplitude 15 milliAmpere) was delivered by a stimulator (Harvard, U.K) being connected to a voltage-to-current convertor circuit using IC (LM 134, U.S.A). The amount of current delivered to each animal was monitored by an oscilloscope (Tektronix, TDS 1002, TEXAS) to ensure that $15 \mathrm{~mA}$ current was being delivered.

\section{Electromyography.}

Evoked surface EMG was recorded from Biceps Femoris (BF) and Gluteus Maximus (GM) muscles on the $3^{\text {rd }}, 7^{\text {th }}, 10^{\text {th }}$ and $14^{\text {th }}$ day after sciatic nerve ligation on the right hind limb. To record, first the electrode sites were shaved and cleaned with alcohol, and the lubricant gel was applied for better conductivity. A pair of recording disposable adhesive Ag-Agcl electrodes (Biopac Company) placed on each end of the muscle (totally 4 electrodes). The fifth electrode (reference) was placed on the vertebral column; the electrodes were taped securely to avoid excessive lead movements. Snap leads were used to connect the electrodes to the amplifier ( 2 channels). All raw myoelectric signals were amplified (band width: 8-1600Hz). Evoked EMG was recorded for $5 \mathrm{sec}$ (5000 samples) during the final 10 sec of the sciatic nerve stimulation. EMG signals were digitized at $1 \mathrm{KHZ}$ with an A/D card (ADVENTECH, 818 PCL -818 HG). Data were collected and saved on a personal computer for statistical analysis. The schematic drawing of the experimental set-up is shown in Figure 1.

\section{Treatment protocols}

To study the effect of electrical stimulation (ES), mice were randomly divided into 3 groups of 10 . Group 1: Ligated without electrical stimulation (non ES-Ligated). In this group sciatic nerve was ligated and allowed to recover naturally. On the $3 \mathrm{rd}, 7 \mathrm{th}, 10 \mathrm{th}$ and 14 th day, surface EMG of BF and GS muscles were recorded in this group. Group 2: Ligated with electrical stimulation (ES-Ligated) or treated group. In this group sciatic nerve was ligated and it was under electrical stimulation daily for a period of 2 weeks. The first ES was just after the surgery. Surface EMG signals were recorded on the 3 rd, 7th, 10th and 14th day after nerve ligation. Group 3: In this control group the sciatic nerve was intact and EMG signals of BF and GS muscles were recorded.

\section{Signal processing}

The raw EMG data were stored and processed off line. The digitized data were viewed before processing to reject those with insufficient signal level or with artefacts. All signal processing was performed using custom programs written with LabView (version 6, National Instruments, Austin, TX). To study muscle power or force, EMG signals were processed in the time domain (Integral Absolute Value: IAV). In this method first signal was rectified and then root mean square (RMS) was obtained and finally linear envelope was determined in order to derive muscle power from the EMG signal. The frequency domain of the surface EMG signals was used to study muscle sensitivity and the number of frequency components was considered as muscle sensitivity index. Increased frequency components of the EMG signal was interpreted as 


\section{Electrical stimulation of ligated sciatic nerve in mice}

Eur J Transl Myol 27 (3): 173-182

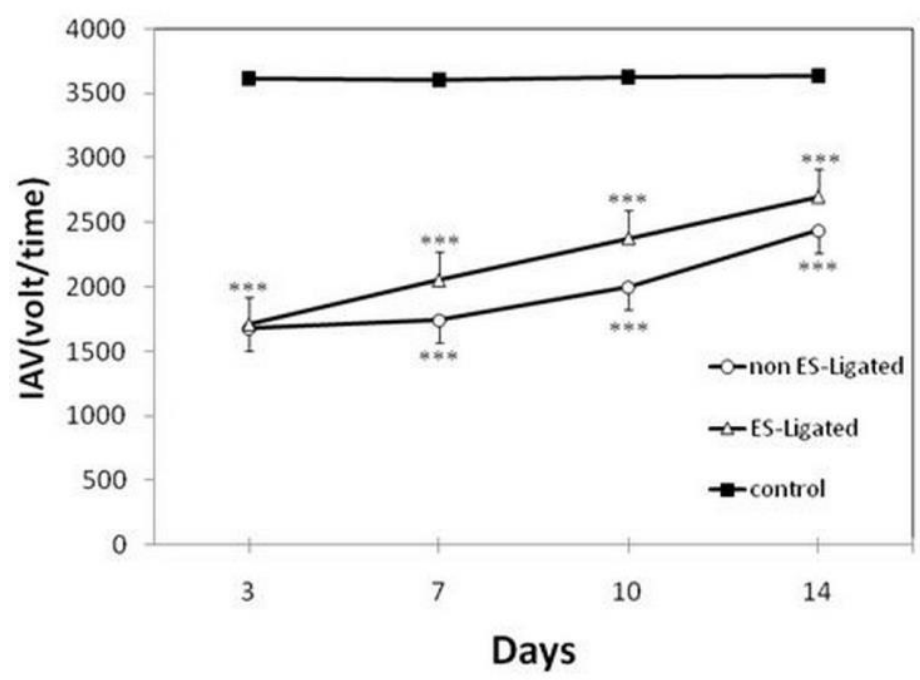

Fig 4. Effect of electrical stimulation on Gluteus maximus muscle force. The EMG signal was recorded on the 3rd, 7th, 10th, 14th day after ligation in non ES- Ligated group (o), ES-Ligated group $(\Delta)$ and control group ( $\square)$. Each point is mean \pm SEM of Integral Absolute Value (IAV) for 10 mice. (*** $\mathrm{p}<0.001$ different from respective control group).

muscle hyperalgesia or muscle hypersensitivity. First Fast Fourier Transform (FFT) of signal was obtained, rectified, filtered, analyzed and finally the number of frequency component were counted using a peak detector. A sample of raw EMG is shown in Figure 2.

\section{Statistical analysis}

Analysis of variance (ANOVA) followed by Tukey test was used to evaluate the significance of the results. All data were expressed in terms of mean \pm standard error of mean (SEM), and $\mathrm{p}<0.05$ was considered to be significant.

\section{Results}

Effect of sciatic nerve stimulation on the muscle force of Biceps Femoris

The effect of electrical nerve stimulation on biceps femoris EMG signals is shown in Figure 3, in which ES-Ligated (ligated with electrical stimulation or treated) and non ES-Ligated (ligated without electrical stimulation) groups compared with each other and with control group. Analysis of variance revealed significant difference between ES-Ligated and non ES-Ligated groups $(\mathrm{p}<0.001)$. There is also a significant difference between the two experimental groups versus control group $(\mathrm{p}<0.001)$. Further analysis showed that there is no significant difference between ES-Ligated and non ES-Ligated groups on the 3rd, 7th, 10th day after ligation. However, the main difference occurred on the 14th day after treatment with ES. A significant increase in the EMG response and muscle force was also obtained $(p<0.001)$ and reaches to $80.9 \%$ of that of control group. Further analysis showed that in ESLigated group, there is a significant gradual increase in muscle force from the 7th day onward. Significant differences between the 7th and 10th day $(\mathrm{p}<0.05)$, 10th and 14 th day $(p<0.001)$, 3rd and 10th day $(p<0.001)$ were observed.

Effect of sciatic nerve stimulation on the muscle force of Gluteus Maximus

The results are shown in Figure 4. There is a significant difference between experimental groups (ES-Ligated and non ES-Ligated) as compared with control group $(p<0.001)$, but no significant difference was found in muscle force between the two experimental groups. Further analysis showed that in ES-Ligated group there is a significant gradual increase in muscle force, i.e., that there are significant differences between the $3^{\text {rd }}$ and $7^{\text {th }}$ day, $7^{\text {th }}$ and $10^{\text {th }}$ day , $10^{\text {th }}$ and $14^{\text {th }}$ day $(\mathrm{p}<0.05)$. In non ES-Ligated group there is significant differences between the $10^{\text {th }}$ and $14^{\text {th }}$ day $(\mathrm{p}<0.01), 3^{\text {rd }}$ and $10^{\text {th }}$ day $(\mathrm{p}<0.01)$, and $7^{\text {th }}$ and $14^{\text {th }}$ day $(\mathrm{p}<0.01)$, but no significant differences were found between the $3^{\text {rd }}$ and $7^{\text {th }}$ day or $7^{\text {th }}$ and $10^{\text {th }}$ day $(\mathrm{p}>0.05)$. No significant differences were found between the other groups

Effect of sciatic nerve stimulation on the sensitivity of Biceps Femoris

The effect of ES on the number of frequency components of EMG signals of BF muscle is shown in Figure 5.The results of ANOVA showed that there is a significant difference between the two experimental groups versus the control group $(p<0.001)$, indicating that the number of frequency components is significantly higher in experimental groups versus control group. There is also significant difference between ES-Ligated and non ES-Ligated groups 


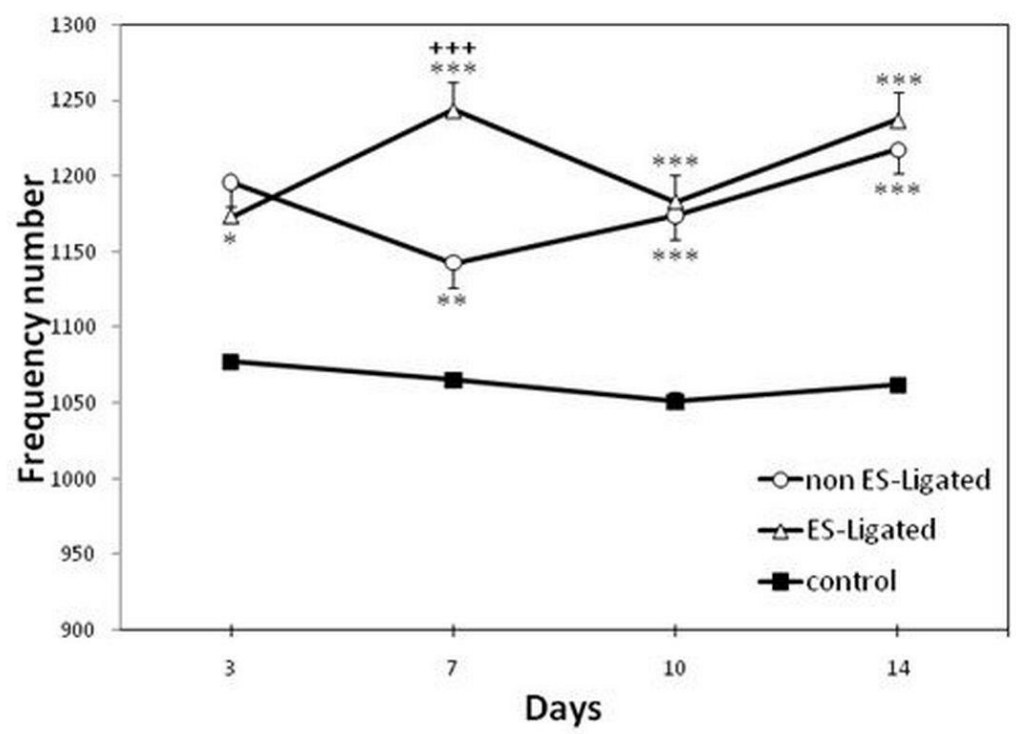

Fig 5. Effect of electrical stimulation on Biceps femoris muscle sensitivity. The EMG signal was recorded on the 3rd, 7th, 10th, 14th day after ligation in non ES-Ligated group (o), ES- Ligated group $(\Delta)$ and control group (匹). Each point is mean \pm SEM of the frequency number for 10 mice. $\left({ }^{*} \mathrm{p}<0.05, * * \mathrm{p}<0.01,{ }^{* * *} \mathrm{p}<0.001\right.$ different from respective control group, $+++\mathrm{p}<0.001$ different from respective non ES-Ligated group).

$(p<0.001)$. Although no difference between these two groups were found on the 14th day ( $p>0.05$ ), on the 7 th day there was a significant difference between experimental groups $(p<0.001)$, thus the number of frequency components is higher in ES-Ligated group. Further analysis between experimental groups showed in non ES-Ligated group there is only significant difference between the 3rd and 14th day $(p<0.05)$, however in ES-Ligated group there is significant difference between the 3rd and 7th day $(\mathrm{p}<0.05)$.

Effect of sciatic nerve stimulation on the sensitivity of Gluteus Maximus

Figure 6 shows the comparison of the effect of ES on the number of frequency components of GM muscle among groups. Analysis of variance did not show significant difference in the number of frequency components between non ES-Ligated with control group ( $>0.05)$, or between ES-Ligated group with control group $(p>0.05)$. No difference was found between the two experimental groups $(\mathrm{p}>0.05)$.

\section{Discussion}

Surface electromyography (SEMG) is a non-invasive method for evaluation of muscle physiology. The time and frequency domains of the signal have been used to examine central and peripheral aspects of neuromuscular physiologic function, as well as the motor unit activation modulate muscular force production. $^{15,19,20}$ The EMG signal amplitude reflects the number of activated motor units and their firing rates, and its frequency contents may be associated with the number of muscle fiber action potentials. ${ }^{21,22}$ Hence evaluation of the repeatability of EMG variables is of considerable relevance for the clinical use of this technique. ${ }^{23}$ In the present study, we have found a significant reduction in muscle power after sciatic nerve ligation. This finding confirms previous data that when muscles lose neural drive, they lose ability to generate force due to atrophy of their muscle fibers. ${ }^{2,10,24,25}$ Our results revealed that sciatic nerve electrical stimulation produced a significant increase in the EMG response of biceps femoris, indicating that its muscle strength increased over time and reached $80.9 \%$ of that of normal muscle at the $14^{\text {th }}$ day after sciatic nerve ligation, thus motor function was recovered better in ES-treated mice. However, non-ES ligated (nontreated) group did not show significant increase in BF muscle power on the $14^{\text {th }}$ day. These results confirm Xu et al. (2014) study that recorded gastrocnemius muscle needle EMG, and reported nerve ES one day after surgery increases muscle action potential parameters such as motor nerve conduction velocity and peak amplitude and decrease latency onset of muscle action potentials. ${ }^{27}$ It seems that ES induces structural changes in the muscle that, in turn, improves muscle function. Our hypothesis confirms other studies indicating that following nerve ES the number of myelinated fibers in distal nerve stump, ${ }^{27}$ the number of regenerated axons, the number of motoneurons and the thickness of myelin sheath were significantly increased as compared to control group. ${ }^{28}$ In accordance with our results, there is evidence indicating that neuromuscular electrical stimulation improved muscle strength. ${ }^{10}$ There is more evidence indicating that ES restores the paralyzed 


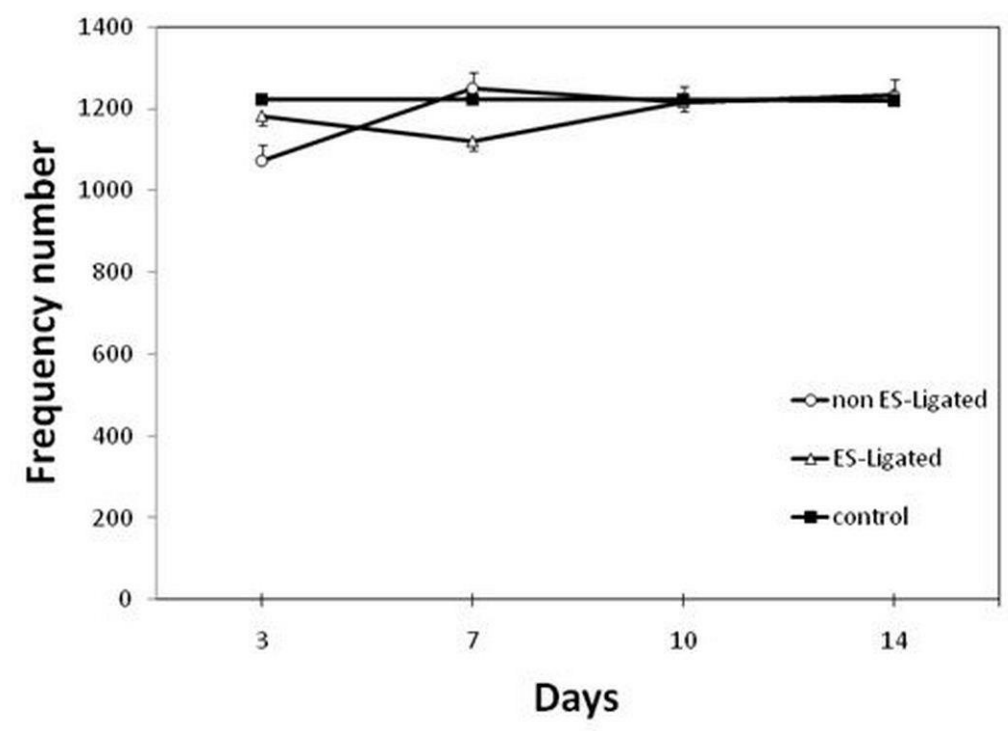

Fig 6. Effect of electrical stimulation on Gluteus Maximus muscle sensitivity. The EMG signal was recorded on the 3rd, 7th, 10th, 14th day after ligation in non ES-Ligated group (o), ES-Ligated group $(\Delta)$ and control group ( $\boldsymbol{\square})$. Each point is mean \pm SEM of the frequency number for 10 mice.

muscle mass, ${ }^{29}$ and evoked visible rhythmic muscle contractions in these muscles. ${ }^{24}$ Even in old muscles, the electrical stimulation can generate tetanic contractions maintaining their mass and maximum force. ${ }^{25}$ Willand et al. (2015) reported that ES of muscle following peripheral nerve injury accelerates muscle reinnervation and its functional behaviors. ${ }^{13}$

The mechanisms by which the electrical stimulation exerts its effect are not clear. However, on the basis of available evidence we conclude that ES may improve muscle function through the following mechanisms. Muscle power is a mechanical quantity which in our experiments was evaluated by evoked EMG. When a nerve is transected and sutured, axonal regeneration from the proximal stump into inappropriate distal pathways after nerve lesion has been long recognized as a factor contributing to poor functional recovery. ${ }^{30}$ Therefore innervation is a critical factor for the support of the structural and functional integrity of skeletal muscles. ${ }^{26}$ A possibility is that in our experiments sciatic nerve ES increases the number of correct projections to the distal stump and to related muscles. This is consistent with the results of Al-Majed et al. (2000) and Brushart et al. (2002) who found that, if the proximal stump of a cut nerve is stimulated at the time of its surgical repair, the speed of reinnervation of target muscles and sensory-motor precisionares were improved. ${ }^{4,31}$ Electrical activity may influence the axonal path finding of developing neurons, ${ }^{32}$ and enhance the speed and accuracy of nerve regeneration. ${ }^{27}$ Therefore ES may be effective in promoting nerve regeneration after peripheral nerve injury. From our results, one may suggest that ES could function as a mechanism to bridge the gap between the nerve stumps electrically and improve muscle force. In other words, the possibility may exists that the ES result in changes in the excitation-contraction coupling mechanism probably be mediated through muscle membrane ion channels which can accelerate depolarization and results synchronized activation of motor units and /or increase of force generating capacity on the $14^{\text {th }}$ day, which is in accordance with finding of Ashley et al. (2007). ${ }^{33}$ Along with these results, it has been suggested that bridging is the best type of peripheral nerve repair. ${ }^{34}$ But what is the molecular mechanism behind this bridging? Another explanation for the effect of ES in our study could be that gene expression of nerve growth factors is increased. Nerve growth factor (NGF) is normally produced in muscle on local injury and inflammation and is known to play a role in regeneration after muscle injury. ${ }^{35}$ Denervation leads to increased NGF production by skeletal muscle, ${ }^{36}$ and ES induces up-regualtion of muscular neurotrophic factors. ${ }^{13,37}$ It has been shown that expression of proteins such as neurotrophins whose release at the level of the muscle might play a key role in determining the accuracy of reinnervation are increased. ${ }^{1,38}$ On the other hand, NGF is involved in regulation of muscle strength. ${ }^{39,40}$ Barmptsioti et al. (2011) reported that NGF administration ensured a significant increase of average number of myelinated axons per $\mu \mathrm{m}$ and lead to better EMG results. ${ }^{41}$ Dose and duration of NGF administration are factors that determine the extent of recovery following peripheral nerve injury. ${ }^{42}$ Zhao et al. (2015) confirmed efficacy 
and safety of nerve growth factor for the treatment of neurological diseases. ${ }^{43}$ Indeed, there is evidence indicating that electrical muscle stimulation increases expression of genes of motor endplate, calcium binding proteins and acethylcholine receptors in muscle following spinal cord lesion. ${ }^{29}$ The present study revealed that ES did not affect GM muscle force. This muscle seems to function differently from BF muscle. This is probably because of its innervation, in fact BF and GM muscles are innervated by different nerves. BF is a double muscle receiving 2 nerves supplies. The nerve to the short head of the BF comes from the common peroneal part of the sciatic nerve, while long head of the muscle is innervated by tibial branch of the sciatic nerve. Whereas, GM is innervated by inferior gluteal nerve. ${ }^{44}$ According to our data, the number of frequency components of $\mathrm{BF}$ muscle that represents muscle sensitivity significantly increased in experimental groups, indicating both of them were hyperalgesic as compared with control group, however there is no difference between experimental groups on the $14^{\text {th }}$ day. This increased EMG activity, muscle hyperalgesia, may be secondary (increased responsiveness to nociceptive stimuli outside the site of injury). Whether the hyperalgesia responses of biceps femoris muscle in the present study is mediated through a cutaneous or visceral mechanism should be clarified. In the present study as can be shown in both ES-Ligated and non ES-Ligated groups, ligation can induce hyperalgesia. According to our data, ES-treated group were becoming hyperalgesic from the $3^{\text {rd }}$ day, and there was a significant difference between treated and nontreated groups on the $7^{\text {th }}$ day (Figure 5). There are data from Hirayama et al. (2001) indicating that electrical stimulus applied to the sciatic nerve in rats was high enough to activate $\mathrm{C}$-fibers and nerve reflexively excited muscles. ${ }^{45}$ However, we do not know whether pain existed on the $7^{\text {th }}$ day of the experiment. Pharmacologic studies are needed to show if this effect will be reverse by analgesic agents used clinically to treat muscle pain. On the other hand, there is some evidence indicating that intramuscular injection of NGF induces hyperalgesia. ${ }^{46-48}$ Furthermore, NGF increases voltage-gated $\mathrm{Na}^{+}$channels activity in excitable cells. ${ }^{49,50}$ It has been reported that the activity of these channels is linked to neuronal excitability in chronic pain states. ${ }^{49}$ As we mentioned before; ES increases NGF production. So, we hypothesize that NGF production is at its maximum level of production at day 7 after ES which result in significant difference between ES-ligated and non ES-ligated mice. This is consistent with the results of Brushart et al. (2002) who found that the use of ES significantly increased the number of axons crossing at the 4 and $7^{\text {th }}$ day, with only a few crossing after 2 weeks. ${ }^{31}$ It is possible that after this day a form of muscle adaptive behavior occurs, indicating repetitive input results in a negative feedback, and the muscle sensitivity return to non-treated level. It has been shown NGF generates secondary hyperalgesia via a central mechanism. ${ }^{46}$ Our results have shown that there was no significant difference in muscle sensitivity of GM between experimental groups with control or between experimental groups. Thus ligation could not induce muscle hyperalgesia in experimental groups. This can be due to innervation of this muscle as mentioned earlier or may be because of less production of mediators involved in hyperalgesia. It seems that both mechanisms may account for this response. Some evidence showed that frequency of ES is an important factor that may determine electrical stimulation effectiveness. ${ }^{51,52}$ In fact, a limitation of our study is that we did not examined the effect of different frequencies. Further research is required to confirm the effectiveness of the nerve electrical stimulation (without stimulation of muscle nociceptors and producing pain) for nerve repair, and precise molecular mechanisms involved.

On the other hand, our results support recent clinical application of Functional Electrical Stimulation (FES) in Spinal Cord Injury (SCI) and aging patients. ${ }^{53-60}$

In conclusion, the results of this study have shown that electrical stimulation of sciatic nerve accelerates through local mechanisms sciatic nerve repair and indirectly improves $\mathrm{BF}$ muscle force to a comparable level of the control without affecting muscle sensitivity. ES of sciatic nerve, indeed, had no effect on force and sensitivity of the GM muscle that is innervated by the inferior gluteal nerve.

\section{List of acronyms}

$\mathrm{BF}$ - Biceps Femoris

EMG - electromyography

ES - electrical stimulation

FES - Functional Electrical Stimulation

FFT - First Fast Fourier Transform

GM - Gluteus Maximus

IAV - Integral Absolute Value

RMS - root mean square

SCI - Spinal Cord Injury

SEM - standard error of mean

SEMG - Surface electromyography

\section{Author's contributions}

Dr. F. Samiee conceived the work, performed the bibliographical search and drafted the manuscript. Dr. M.-R. Zarrindast approved the research and the final manuscript.

\section{Acknowledgments}

The technical assistance of Mr. Hamidreza Taghavi is gratefully acknowledged.

\section{Ethical Publication Statement}

We confirm that we have read the Journal's position on issues involved in ethical publication and affirm that this report is consistent with those guidelines. 


\section{Electrical stimulation of ligated sciatic nerve in mice}

Eur J Transl Myol 27 (3): 173-182

\section{Conflict of Interest}

None of the authors have conflicts of interests.

\section{Corresponding Author}

Farzaneh Samiee, Biomedical Engineering Faculty, Science and Research Branch, Islamic Azad University, Tehran, Iran. Phone:+98912 1967190

E-mail: f.samiee@yahoo.com

\section{E-mails of co-author}

ZarrindastMohammad-Reza: zarinmr@ams.ac.ir

\section{References}

1. Voria I, Hauser J, Axis A, et al. Improved sciatic nerve regeneration by local thyroid hormone treatment in adult rat is accompanied by increased expression of SCG 10. Exp Neurol 2006;197;25867.

2. Jonsson S, Wiberg R, McGrath AM, et al. Effect of delayed peripheral nerve repair on nerve regeneration, Schwann cell function and target muscle recovery. PloS one 2013; 8 (2):e56484

3. Grinsell D, Keating CP. Peripheral nerve reconstruction after injury: a review of clinical and experimental therapies. Biomed Res Int 2014;2014:698256. doi: 10.1155/2014/698256.

4. Al- Majed AA, Neumann CM, Brushart TM, Gordon T. Brief electrical stimulation promotes the speed and accuracy of motor axonal regeneration. J Neurosci 2000;20:2602-8.

5. Liu S, Li H, Yang JO, et al. Enhanced rat sciatic nerve regeneration through silicon tubes filled with pyrroloquinoline quinine. Microsurgery 2005;25;329-37.

6. Mendonça AC, Barbieri, CH, Mazzer, N. Directly applied low intensity direct electric current enhances peripheral nerve regeneration in rats. J Neurosci Methods 2003;129:183-90.

7. Teodori RM, Silva AM, Silva MT, et al. Highvoltage electrical stimulation improves nerve regeneration after sciatic crush injury. Rev Bras Fisioter 2011;15:325-31. Epub 2011 Aug 5.

8. Gall C, Schmidt S, Schittkowski MP, et al. Alternating Current Stimulation for Vision Restoration after Optic Nerve Damage: A Randomized Clinical Trial. PloS One 2016;11:e0156134 doi: 10.1371/journal.pone. 0156134. eCollection 2016.

9. Cavalcante Miranda de Assis D, Martins Lima Ê Teixeira Goes B, et al. The Parameters of Transcutaneous Electrical Nerve Stimulation Are Critical to Its Regenerative Effects When Applied Just Sciatic Crush Lesion in Mice. Biomed Res Int 2014;2014:572949. doi: 10.1155/2014/572949. Epub 2014 Jul 24.

10. Doucet BM, Lam A, Griffin L. Neuromuscular electrical stimulation for skeletal muscle function. Yale J Biol Med 2012;85:201-15.
11. Chen TY, Yang YC, Sha YN, et al. Far-Infrared Therapy Promotes Nerve Repair following End-toEnd Neurorrhaphy in Rat Models of Sciatic Nerve Injury. Evid Based Complement Alternat Med 2015;2015:207245. doi: 10.1155/2015/207245.

12. Willand MP, Holmes M, Bain JR., et al. Determining the effects of electrical stimulation on functional recovery of denervated rat gastrocnemius muscle using motor unit number estimation. In Annual International Conference of the IEEE Engineering in Medicine and Biology Society 2011; (pp. 1977-1980).

13. Willand MP. Electrical stimulation enhances reinnervation after nerve injury. Eur J Transl Myol 2015;25:243.

14. Gigo-Benato D, Russo TL, Geuna S, et al. Electrical stimulation impairs early functional recovery and accentuates skeletal muscle atrophy after sciatic nerve crush injury in rats. Muscle Nerve 2010;41:685-93.

15. Mathur S, Eng JJ, Macintyre DL. Reliability of surface EMG during sustained contractions of the quadriceps. J Electromyogr Kinesiol 2005;15:10210.

16. Place N, Martin A, Ballay Y, Lapers R. Neuromuscular fatigue differs with biofeedback type when performing a submaximal contraction. J Electromyogr Kinesiol 2007;17:253-63.

17. Bennet GJ, Xie YK. A peripheral mononeuropathy in rat that produces disorders of pain sensation like those seen in man. Pain 1988;33;87-107.

18. Attal N, Jazat F, Kayser V, Guilbaud G. Further evidence for 'pain-related' behaviours in a model of unilateral peripheral mononeuropathy. Pain 1990;41: 235-51.

19. Cramer JT, Housh TJ, Weir JP, et al. Power output, Mechanomyographic, and electromyographic responses to maximal, concentric, isokinetic muscle actions in men and women. $\mathbf{J}$ Strength Cond Res 2002;16:399-408.

20. Beck TW, Housh TJ, Johnson GO, et al. Mechanomyographic and electromyographic time and frequency domain responses during submaximal to maximal isokinetic muscle actions of the biceps brachii. Eur J Appl Physiol 2004;92:352-9.

21. Malek MH, Coburn JW, Wier JP, et al. The effects of innervations zone on electromyographic amplitude and mean power frequency during incremental cycle ergometry .J Neurosci Methods 2006;155:126-33.

22. Boe SG, Rice CL. and Doherty TJ. Estimating contraction level using root mean square amplitude in control subjects and patients with neuromuscular disorders. Arch Phys Med Rehabil. 2008;89:711-8. doi: 10.1016/j.apmr.2007.09.047.

23. Kelis E, Katis A. Reliability of EMG powerspectrum and amplitude of the semitendinosus and 


\section{Electrical stimulation of ligated sciatic nerve in mice}

Eur J Transl Myol 27 (3): 173-182

biceps femoris muscles during ramp isometric contraction. J Electromyo Kinesiol 2008;18:351-8.

24. Salter AD, Richmond FJ, Loeb GE. Prevention of muscle disuse atrophy by low-frequency electrical stimulation in rats. IEEE Transactions on neural systems and rehabilitation engineering 2003;11;218-26.

25. Dow DE, Dennis RG, Faulkner JA. Electrical stimulation attenuates denervation and age-related atrophy in extensor digitorum longus muscles of old rats. J Gerontol, series :Biological sciences 2005;60 A:416-24.

26. Kostrominova TY, Dow DE, Dennis RG, et al. Comparison of gene expression of 2-mo denervated , 2-mo stimulated-denervated, and control rat skeletal muscles. Physiol Genomics 2005;22:227-243.

27. Xu C, Kou Y, Zhang P, et al. Electrical stimulation promotes regeneration of defective peripheral nerves after delayed repair intervals lasting under one month. PloS One 2014;9: p.e105045.

28. Huang J, Zhang Y, Lu L, et al. 2013. Electrical stimulation accelerates nerve regeneration and functional recovery in delayed peripheral nerve injury in rats. Eur J Neurosci 2013;38:3691-701.

29. Wu Y, Collier L, Qin W, et al. Electrical stimulation modulates Wnt signaling and regulates genes for the motor endplate and calcium binding in muscle of rats with spinal cord transection. BMC Neurosci 2013;14:1.

30. Sulaiman W, Gordon T. Neurobiology of peripheral nerve injury, regeneration, and functional recovery: from bench top research to bedside application. The Ochsner Journal 2013;13:100-8.

31. Brushart TM, Hoffman PN, Royal RM, et al. Electrical stimulation promotes motoneuron regeneration without increasing its speed or conditioning neuron. J Neurosci 2002;22:6631-8.

32. Ming GL, Henley J, Lavigne MT, et al. Electrical activity modulates growth cone guidance by diffusible factors. Neuron 2001;29:441-52.

33. Ashley Z, Sutherland H, Lanmüller $H$, et al. Atrophy, but not necrosis, in rabbit skeletal muscle denervated for periods up to one year. Am J Physiol-Cell Physiol 2007;292:C440-51.

34. Oliveria EF, Mazzer N, Barbieri CH, DelBel EA. The use of a muscle graft to repair a segmentary nerve defect an experimental study using the sciatic nerve of rats as model. J Neurosci Methods 2004;133:19-26.

35. Menderes A, Ylmaz M, Vayvada H, et al. Effects of nerve growth factor on the neurotization of denervated muscles. Ann Plastic Surg 2002;48:415-22.

36. Kingham PJ, Terenghi G. Bioengineered nerve regeneration and muscle reinnervation. J Anat 2006;209:511-26.
37. Chang $\mathrm{YJ}$, Hsu CM, Lin $\mathrm{CH}$, et al. Electrical stimulation promotes nerve growth factor-induced neurite outgrowth and signaling. Biochimica et Biophysica Acta (BBA)-General Subjects 2013;1830:4130-6.

38. Johnson EO, Zoubos AB, Soucacos PN. Regeneration and repair of peripheral nerves. Injury 2005;365:S24-9.

39. Chen J, von Bartheld CS. Role of exogenous and endogenous trophic factors in the regulation of extraocular muscle strength during development. Investigative ophthalmology \& visual science 2004;45:3538-45.

40. Chen YS. Effects of electrical stimulation on peripheral nerve regeneration. BioMedicine 2011;1:33-6.

41. Barmpitsioti A, Konofaos P, Ignatiadis I, et al. Nerve growth factor combined with an epineural conduit for bridging a short nerve gap $(10 \mathrm{~mm})$. A study in rabbits. Microsurgery 2011;31:545-50.

42. Kemp S.W, Webb A.A, Dhaliwal S, et al. Dose and duration of nerve growth factor (NGF) administration determine the extent of behavioral recovery following peripheral nerve injury in the rat. Exp Neurol 2011;229:460-70.

43. Zhao M, Li X.Y, Xu C, et al. Efficacy and safety of nerve growth factor for the treatment of neurological diseases: a meta-analysis of 64 randomized controlled trials involving 6297 patients. Neural regeneration research 2015;10:819.

44. English AW. Development of compartmentalized innervation of the gluteus maximus muscle. J Com Neurol 1990;301:104-13.

45. Hirayama J, Takahashi Y, Nakajima Y, et al. Effect of electrical stimulation of the sciatic nerve on background electromyography and static stretch reflex activity of trunk muscles in rats. Spine 2001; 26:602-9.

46. Hathway G.J and Fitzgerald M. Time course and dose-dependence of nerve growth factor-induced secondary hyperalgesia in the mouse. J Pain 2006;7:57-61.

47. Andersen H, Arendt- Nielsen L, et al. Spatial and temporal aspects of muscle hyperalgesia induced by nerve growth factor in humans. Exp Brain Res 2008;191:371-82.

48. Hayashi K, Ozaki N, Kawakita K, et al. Involvement of NGF in the rat model of persistent muscle pain associated with taut band. J Pain 2011;12;1059-68.

49. Eijkelkamp N, Linley J.E, Baker MD, et al. Neurological perspectives on voltage-gated sodium channels. Brain 2012;135:2585-612.

50. Koltai T. Voltage-gated sodium channel as a target for metastatic risk reduction with re-purposed drugs. F1000Res. 2015;4:297. doi: 10.12688/f1000research.6789.1. eCollection 2015. 
51. Somers DL. Transcutaneous Electrical Nerve Stimulation for the Management of Neuropathic Pain: The Effects of Frequency and Electrode Position on Prevention of Allodynia in a Rat Model of Complex Regional Pain Syndrome Type II. Phys Ther 2006;86:698-709.

52. Vance CGT, Radhakrishnan R, Skyba DA, Sluka, K.A. Transcutaneous electrical nerve stimulation at both high and low frequencies reduces primary hyperalgesia in rats with joint inflammation in a time-dependent manner. Phys Ther 2007;87:44-51.

53. Kern H, Stramare R, Martino L, et al. Permanent LMN denervation of human skeletal muscle and recovery by h-b FES: management and monitoring. Eur J Transl Myol 2010; 1:91-104.

54. Edmunds KJ, Árnadóttir Í, Gíslason MK, et al. Nonlinear Trimodal Regression Analysis of Radiodensitometric Distributions to Quantify Sarcopenic and Sequelae Muscle Degeneration. Comput Math Methods Med 2016;2016:8932950. doi: 10.1155/2016/8932950. Epub 2016 Dec 27.

55. Coste CA, Mayr W, Bijak M, et al. FES in Europe and Beyond: Current Translational Research. Eur J
Transl Myol 2016 Dec 16;26(4):6369. doi: 10.4081/ejtm.2016.6369. eCollection 2016 Sep 15.

56. Carraro U, Kern H, Gava P, et al. Recovery from muscle weakness by exercise and FES: lessons from Masters, active or sedentary seniors and SCI patients. Aging Clin Exp Res 2016 Sep 3. [Epub ahead of print] Review.

57. Carraro U. 2017Spring PaduaMuscleDays, roots and byproducts. Eur J Transl Myol 2017;27:6810. doi: 10.4081/ejtm.2017.6810. eCollection 2017 Jun 24.

58. Kern H, Hofer C, Loefler S, et al. Atrophy, ultrastructural disorders, severe atrophy and degeneration of denervated human muscle in SCI and Aging. Implications for their recovery by Functional Electrical Stimulation, updated 2017. Neurol Res 2017;39:660-6.

59. Cvecka J, Tirpakova V, Sedliak M et al () Physical activity in elderly. Eur J Transl Myol 2015;25:249-52.

60. Sarabon N, Löfler S, Hosszu G, Hofer C Mobility test protocols for the elderly: a methodological note. Eur J Transl Myol 2015;25:253-6. 